

\title{
NUTRITION AND MENTAL HEALTH-HOW THE FOOD WE EAT CAN AFFECT OUR MOOD
}

\section{Melissa Eaton ${ }^{1 *}$, Joseph Firth ${ }^{1,2}$ and Jerome Sarris ${ }^{1,3}$}

${ }^{1}$ NICM Health Research Institute, Western Sydney University, Sydney, NSW, Australia

${ }^{2}$ Divison of Psychology and Mental Health, Faculty of Biology, Medicine and Health, The University of Manchester, Manchester, United Kingdom

${ }^{3}$ Professorial Unit, Department of Psychiatry, The Melbourne Clinic, Melbourne University, Melbourne, VIC, Australia

YOUNG REVIEWER:

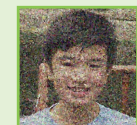

WINSTON

AGE: 14
Food is vital for our survival, it gives us energy, helps us grow, and keeps us healthy. But can it also affect our mood? Science says it can. In the past, a great deal of research has explored how food can affect our physical health. Although this is important, exciting research is now exploring how food can influence our mood and our mental health. Mental health conditions, such as depression affect a significant number of people. This makes research into the effects of food and mood crucial, as food may offer a strategy to help prevent people from getting depression and also help them when they already have depression. Although we are not yet able to explain the exact ways in which food may affect our mood, this research has the potential to decrease the number of people who suffer from mental health conditions, such as depression. 
MAJOR DEPRESSIVE DISORDER (MDD)

A type of depressive disorder, otherwise known as clinical depression, that may be mild, moderate or severe.

\section{MENTAL HEALTH}

A person's psychological and emotional well-being.

\section{WHAT IS DEPRESSION?}

Depression is a type of illness that influences how we feel. It may develop slowly over time with no external cause and, unlike a physical injury or illness, we cannot always see it just by looking at someone. This is because depression affects the parts of the brain that control how we feel. Diseases that affect our feelings, thoughts and behaviors are called mental illnesses, so depression is a type of mental illness.

We all have times when we feel happy or sad. However, for someone with depression, the feelings of sadness or low mood do not go away. Depression is more than just being sad or down, or losing interest in activities that were once enjoyed, and it can affect everyone in a different way-symptoms are often unique to each individual. A person might, for instance, feel tired all the time and not have much energy, or might find it hard to concentrate. A depressed person may have changes in sleep patterns, have feelings of guilt or low self-worth, or even have changes in appetite [1]. Symptoms can vary in severity, from rather minor depressive symptoms up to something called major depressive disorder (MDD), which is a diagnosed clinical condition where multiple symptoms may last for a long time.

Depression is an important mental illness to study, because it affects more than 300 million people from all around the world [1]. It is one of the most common mental health conditions and can affect both men and women [1]. In fact, it is predicted that depression will be the number one health concern in the world by the year 2030 [2]. These statistics show just how important it is to find ways to help prevent people from developing depression and to help people who already have depression.

There are currently a number of ways depression can be treated. One method includes taking a variety of medications. Another includes talking to specialists, such as psychologists, who are trained in treating mental health issues. Although these methods can be effective, there are many people who cannot access these treatments because of where they live, their income, the availability of specialists, or stigma and shame [1]. Even when people do have access to these treatment methods, some people who try them do not recover completely $[1,3]$. For this reason, it is important to find other ways to help people with depression. For example, the food that we eat is one factor that might influence our mental health and our mood.

\section{WHAT IS NUTRITION?}

There are many different components that make up the food that we eat. These include a range of nutrients and chemicals, such as macro and micronutrients. Macronutrients are nutrients we need a 
Figure 1

Dietary improvement can lead to better mental health and better physical health. Mental health and physical health also affect each other.

\section{ANTIOXIDANTS}

Plant compounds that protect cells from damage.

\section{NUTRITION}

The science that looks at the effects of food on the human body.

\section{TRANS FAT}

A type of fat that has been shown by researchers to be unhealthy for your heart.

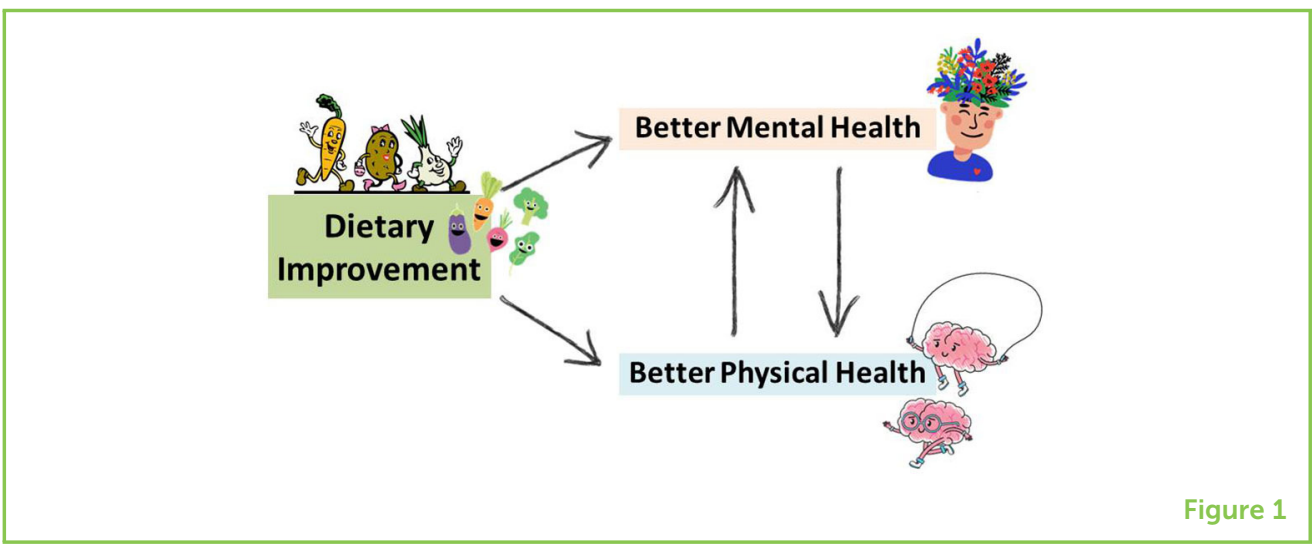

lot of in our diets and they include carbohydrates, proteins, and fats. Micronutrients are nutrients we need in smaller amounts and they include vitamins and minerals. Along with these nutrients, there are many other important components of food including fiber, water, and antioxidants. These components work together to contribute to the healthy functioning of the human body.

The food we eat can give us energy, help us grow, and keep us healthy-but nutrition involves much more than this. The field of nutrition considers whether people can access and afford to buy food, how foods vary across different cultures, and why we choose to eat the foods that we do. In fact, new ideas about the effects of food are being explored all the time. One idea that is of great importance is how the food we eat can affect our mood. It is possible that the components in food, such as vitamins and minerals, can influence depression. It also explores how depression can influence our food choices [4]. Figure 1 highlights the connections between what we eat and our mental and physical health.

\section{FOOD AND MOOD}

Researchers have looked at the connection between diet and depression, and there is now a great deal of evidence suggesting that what we eat every day can influence our mood $[4,5]$. This research shows that a healthy dietary pattern, such as a Mediterranean-style diet, can have a positive effect on mental health $[4,5]$. A typical healthy diet pattern is shown in Figure 2. This includes plenty of vegetables, fruit, nuts, seeds, and olive oil, as well as minimally processed whole grains, legumes, and moderate amounts of lean meat, fish, and dairy. A healthy diet is also low in added sugar and saturated and trans fats, and is high in fiber and antioxidants [3].

Recent studies have explored the link between this healthy dietary pattern and depression. These studies collected information from a large number of people over time. This dietary research has shown a link between unhealthy dietary patterns and symptoms of depression. 
Figure 2

A typical healthy dietary pattern includes vegetables, fruit, whole grains, lean meats, dairy, and healthy fats.

ULTRA-PROCESSED FOODS

Foods that have been highly manipulated and have ingredients added that are not usually used in cooking, such as artificial colors and flavors.

\section{GUT MICROBIOME}

The community of different bacteria and microorganisms living in the intestine.

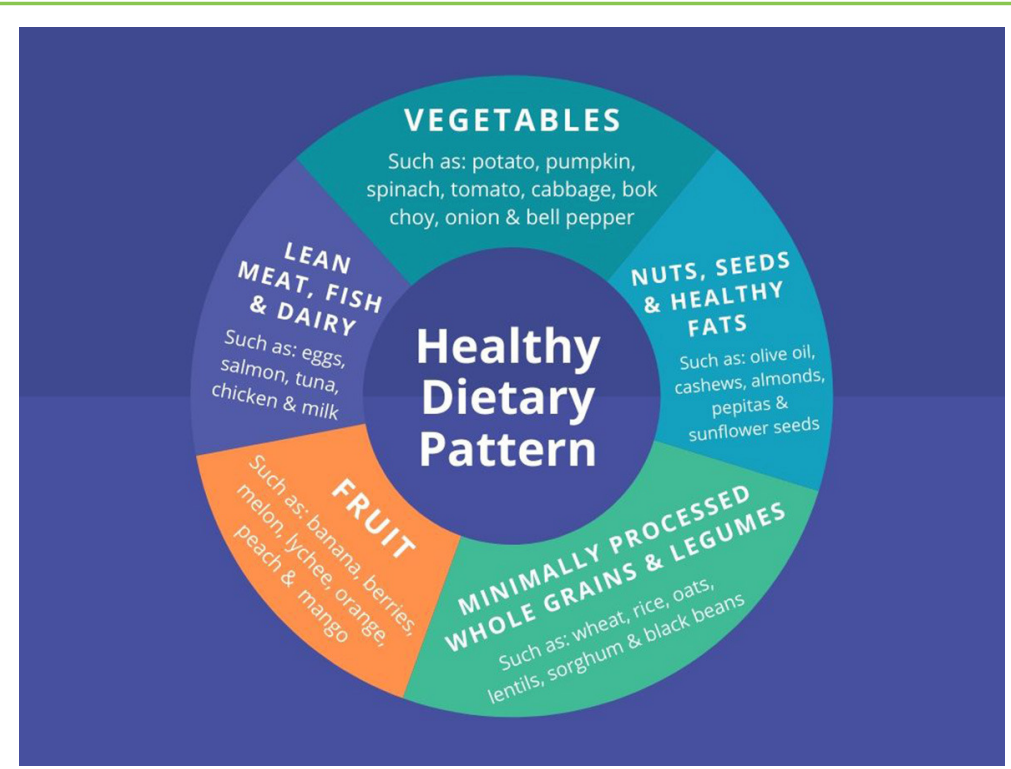

Figure 2

An unhealthy diet contains mainly ultra-processed foods, including sugar-sweetened beverages, such as soft drinks and packaged snacks that are high in added sugar, salt, and saturated and trans fats. The discovery of this link between diet and depression is important because it suggests that following a healthy dietary pattern over time could possibly prevent depression $[4,5]$.

Other research has shown that a healthy dietary pattern may be able to treat depression. This research looked at the effect of a healthy dietary pattern on people who already had depression. In this Australian study, the researchers compared the results of two different groups of people with depression. Only one group was taught how to follow a healthy dietary pattern. Researchers then looked to see if the changes in their diets improved their mood compared with the group that was not taught to follow a healthy diet. The study showed that people who followed a healthy dietary pattern for 3 months reduced their symptoms of depression [5].

\section{WHY DOES FOOD HELP WITH DEPRESSION?}

We are not yet able to explain exactly how food may positively affect our mood. However, there are a number of theories as to why this might be the case. Some theories explore the function of different components of food, such as vitamins, minerals, and antioxidants. These theories focus on the role these micronutrients play in contributing to the healthy functioning of the human body. Other theories look at the importance of the microorganisms that live in the gut, called the gut microbiome, and how the foods we eat can affect this microbiome. Lastly, other theories suggest that the changes in behavior that happen when people start to eat a healthy 
diet may provide the beneficial effects on mood. These behavioral changes could include cooking more at home or cooking and eating in a social setting [5]. The positive experiences associated with the cultural and social aspect of food may help with depressive symptoms. Remember, nutrition is more than just food giving us energy, keeping us healthy and helping us grow-it is also about foods from different cultures, and why we choose to eat the foods that we do. Therefore, cooking in a social setting may not only influence food choice but may also contribute to a positive food experience and a healthy social environment. Cooking more at home may also help to promote more frequent, healthier food choices.

Finally, there are some studies that look at more specific diets (such as a vegetarian diet) and mental health, but this is not something that has been explored in great detail yet. It would be interesting if more research were done on this subject in the future.

\section{SUMMARY: THE FOOD WE EAT CAN AFFECT OUR MOOD}

In conclusion, the food we eat is not only important for our physical health, but also for our mental health. Although more studies are needed to help understand how and why this may be the case, there is now plenty of research that shows what we eat can influence our mood. This suggests diet may be able to play an important role in the prevention and treatment of depression, one of the most common mental health conditions in the world.

\section{AUTHOR CONTRIBUTIONS}

ME drafted the manuscript and approved the final version. JF contributed to the drafting of the manuscript and has approved the final version. JS contributed to the drafting of the manuscript and has approved the final version.

\section{REFERENCES}

1. Lim, G. Y., Tam, W. W., Lu, Y., Ho, C. S., Zhang, M. W., and Ho, R. C. 2018. Prevalence of depression in the community from 30 countries between 1994 and 2014. Sci. Rep. 8:2861. doi: 10.1038/s41598-018-21243-x

2. World Health Organization. 2008. The Global Burden of Disease: 2004 Update. Geneva: World Health Organization.

3. Firth, J., Marx, W., Dash, S., Carney, R., Teasdale, S. B., Solmi, M., et al. 2019. The effects of dietary improvement on symptoms of depression and anxiety: a meta-analysis of randomized controlled trials. Psychosom. Med. 81:265. doi: 10.1097/PSY.0000000000000673

4. Sarris, J., Logan, A. C., Akbaraly, T. N., Paul Amminger, G., Balanzá-Martínez, V., Freeman, M. P., et al. 2015. International Society for Nutritional Psychiatry 
Research consensus position statement: nutritional medicine in modern psychiatry. World Psychiatry 14:370-1. doi: 10.1002/wps.20223

5. Jacka, F. N., O'Neil, A., Opie, R., Itsiopoulos, C., Cotton, S., Mohebbi, M., et al. 2017. A randomised controlled trial of dietary improvement for adults with major depression (the 'SMILES' trial). BMC Med. 15:23. doi: 10.1186/s12916-0170791-y

SUBMITTED: 11 October 2019; ACCEPTED: 24 July 2020; PUBLISHED ONLINE: 11 September 2020.

EDITED BY: Jorge Galindo-Villegas, Nord University, Norway

CITATION: Eaton M, Firth J and Sarris J (2020) Nutrition and Mental Health-How the Food We Eat Can Affect Our Mood. Front. Young Minds 8:115. doi: 10.3389/ frym.2020.00115

CONFLICT OF INTEREST: JF is supported by a University of Manchester Presidential Fellowship (P123958) and a UK Research and Innovation Future Leaders Fellowship (MR/T021780/1) and has received support from a NICM-Blackmores Institute Fellowship. JS has received either presentation honoraria, travel support, clinical trial grants, book royalties, or independent consultancy payments from: Integria Healthcare \& MediHerb, Pfizer, Scius Health, Key Pharmaceuticals, Taki Mai, FIT-BioCeuticals, Blackmores, Soho-Flordis, Healthworld, HealthEd, HealthMasters, Kantar Consulting, Grunbiotics, Research Reviews, Elsevier, Chaminade University, International Society for Affective Disorders, Complementary Medicines Australia, SPRIM, Terry White Chemists, ANS, Society for Medicinal Plant and Natural Product Research, Sanofi-Aventis, Omega-3 Center, the National Health and Medical Research Council, CR Roper Fellowship.

The remaining author declares that the research was conducted in the absence of any commercial or financial relationships that could be construed as a potential conflict of interest.

COPYRIGHT @ 2020 Eaton, Firth and Sarris. This is an open-access article distributed under the terms of the Creative Commons Attribution License (CC BY). The use, distribution or reproduction in other forums is permitted, provided the original author(s) and the copyright owner(s) are credited and that the original publication in this journal is cited, in accordance with accepted academic practice. No use, distribution or reproduction is permitted which does not comply with these terms.

\section{YOUNG REVIEWER}

\section{WINSTON, AGE: 14}

My name is Winston and I was born and raised in the US. In my spare time, I enjoy watching the news, playing piano, and playing basketball. My favorite basketball team is whatever team Lebron is on. 

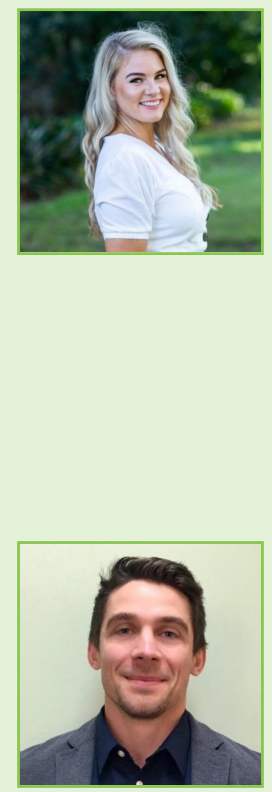

\section{AUTHORS}

\section{MELISSA EATON}

I am an Associate Nutritionist (ANutr.), and former Secondary School Teacher, with a Bachelor of Science (Nutrition \& Food Science) and soon to complete a Master of Nutrition \& Dietetics. My main interests include the role of diet and nutrition in mental health including depression and anxiety, as well as disordered eating and the importance of having a healthy relationship with food. I am also interested in behavior change and exploring how the internet and social media may influence these conditions. Outside of work, I love to stay active by going to the gym, dancing, reformer pilates, and indoor rock climbing. I also love cooking, baking, and traveling to different countries. *m.eaton@ awesternsydney.edu.au

\section{JOSEPH FIRTH}

I am a Research Fellow at the University of Manchester and Honorary Research Fellow at Western Sydney University. My research focuses on physical activity interventions for improving physical and mental health in people with psychiatric conditions. I also investigate nutritional interventions for mental health, and the potential for using digital technologies (including $\mathrm{mHealth}$ ) to facilitate and improve mental healthcare. Outside of work, I enjoy traveling to different countries, taking part in various sports, and fitness training. I hope my research will help to improve the care that young people with mental illness receive, particularly with protecting their physical health and aiding their long-term recovery.

\section{JEROME SARRIS}

I am a Professor in the mental health field at the NICM Health Research Institute at Western Sydney University. My research focuses on the evidence-based use of nutrients and plant medicines and lifestyle changes to improve mood and reduce anxiety. Outside of work I enjoy a range of healthy activities including yoga, meditation, boxing, gym, swimming, sauna, and cooking nice food. I like to play guitar and to sing, as well as to get out in the garden and nature. I hope my research will help people to have more skills and interventions to enhance their mental health. 